Case report

\title{
Effective palliative radiotherapy in primary malignant melanoma of the esophagus: a case report
}

Takeshi Nonoshita ${ }^{1}$, Yoshiyuki Shioyama ${ }^{1}$, Satoshi Nomoto ${ }^{1}$, Saiji Ohga ${ }^{1}$, Kayoko Ohnishi ${ }^{1}$, Kazushige Atsumi ${ }^{1}$, Kotaro Terashima ${ }^{1}$, Shuji Matsuura ${ }^{1}$, Katsumasa Nakamura ${ }^{2}$, Hideki Hirata ${ }^{3}$ and Hiroshi Honda ${ }^{1}$

\author{
Addresses: ${ }^{1}$ Department of Clinical Radiology, Graduate School of Medical Sciences, Kyushu University, Fukuoka, Japan \\ ${ }^{2}$ Department of Radiology, Fukuoka University School of Medicine, Fukuoka, Japan \\ ${ }^{3}$ Department of Radiologic Technology, School of Health Sciences, Kyushu University, Fukuoka, Japan \\ Email: TN* - takenono@radiol.med.kyushu-u.ac.jp; YS - shioyama@radiol.med.kyushu-u.ac.jp; SN - s-nomoto@radiol.med.kyushu-u.ac.jp; \\ SO - saiji@radiol.med.kyushu-u.ac.jp; KO - konishi@radiol.med.kyushu-u.ac.jp; KA - kaatsumi@radiol.med.kyushu-u.ac.jp; \\ KT - kohta_t@radiol.med.kyushu-u.ac.jp; SM - smatsu@radiol.med.kyushu-u.ac.jp; KN - nakam@giga.ocn.ne.jp; \\ HH - hideki@radiol.med.kyushu-u.ac.jp; HH - honda@radiol.med.kyushu-u.ac.jp \\ * Corresponding author
}

Received: 27 March 2009 Accepted: 3 August 2009 Published: 19 August 2009

Cases Journal 2009, 2:6928 doi: 10.4076/1757-1626-2-6928

This article is available from: http://casesjournal.com/casesjournal/article/view/6928

(C) 2009 Nonoshita et al.; licensee Cases Network Ltd.

This is an Open Access article distributed under the terms of the Creative Commons Attribution License (http://creativecommons.org/licenses/by/3.0), which permits unrestricted use, distribution, and reproduction in any medium, provided the original work is properly cited.

\begin{abstract}
Introduction: Primary malignant melanoma of the esophagus is a rare but highly aggressive tumor with poor prognosis. Surgical resection is the treatment of choice. However, some cases may be diagnosed with advanced inoperable disease. Palliative radiotherapy may be used to relieve symptoms caused by the esophageal tumor.

Case presentation: We report on a case of advanced inoperable primary malignant melanoma of the esophagus treated with palliative radiotherapy. The patient's dysphagia resolved with radiotherapy.

Conclusion: Malignant melanoma of the esophagus is rare. Patients with advanced inoperable malignant melanomas of the esophagus benefit from radiation therapy. Radiation therapy is effective for palliation.
\end{abstract}

\section{Introduction}

Primary malignant melanoma of the esophagus is an uncommon disease accounting for only $0.1 \%$ to $0.5 \%$ of all esophageal carcinomas [1-3]. It has a highly aggressive tumor behavior with a median survival of about 10 months [4]. Some patients are inoperable at presentation. Radiation therapy has been used to relieve symptoms. Malignant melanomas are generally considered radioresistant, requiring higher dose per fraction. We report on a case of primary malignant melanoma of the esophagus treated with palliative radiotherapy.

\section{Case presentation}

A 71-year-old male subject presented to us in very poor general condition (Eastern Cooperative Oncology Group performance status 3) with a history of hoarseness 
(3 months) and dysphagia (1 month). Clinically, the left supraclavicular lymph node $(3 \times 3 \mathrm{cms})$ was palpable. Computed tomography (CT) scan of the chest and abdomen demonstrated extensive swelling of the mediastinal lymph nodes extending from $4 \mathrm{~cm}$ above the level of the upper margin of the sternum to $2 \mathrm{~cm}$ below the carina, the esophagus was compressed and trachea shifted to the right of the midline. Primary esophageal tumor was not separately identifiable from the mediastinal lymph nodes. Lymph nodes in the superior and middle mediastinum measured approximately $12 \times 7.7 \times$ $6.0 \mathrm{~cm}$ (Figure 1A). Left supraclavicular $(3.3 \times 3.0 \mathrm{~cm})$ and abdominal node $(1.9 \times 1.5 \mathrm{~cm})$ metastases were also observed (Figure 1B, 1C). Esophagoscopy demonstrated a $10 \mathrm{~mm}$ pigmented polypoidal lesion $(25 \mathrm{~cm}$ from the inscisor) and multiple pigmented flat lesions (Figure 2). Esophageal narrowing due to extrinsic compression was seen from $19 \mathrm{~cm}$ to $24 \mathrm{~cm}$. Histopathology of the biopsy specimen from the esophagus showed diffuse proliferation of atypical polygonal cells with hyperchromatic oval to round nuclei, eosinophilic cytoplasm, and prominent nucleoli, accompanied by various amounts of melanin pigments and immunohistochemically - positive for S-100 protein. These findings were all compatible with malignant melanoma of the esophagus. A final diagnosis malignant melanoma of the esophagus T4N1M1a, stage IVa (UICC-TNM classification [5]) was made.

Due to the fact that PS was 3, palliative radiotherapy was offered for palliation of dysphagia and tracheal compression and chemotherapy was not administrated. He received radiation therapy for primary tumor and mediastinal and left supraclavicular lymph nodes in a dose of 45 Gy (gray) in 15 fractions over 3weeks at 5 fractions per week, using anteroposterior and posteroanterior field with10-MV photon. Patient tolerated the radiotherapy well. The patient's dysphagia resolved completely shortly after radiotherapy. 1 week after radiotherapy there was a marked decrease in the size of the mediastinal lymph nodes and subject improved symptomatically. The axial dimensions of the lymph node were maximal around the level of the aortic arch where it measured approximately $4.5 \times 3.5 \mathrm{~cm} 1$ week following completion of radiotherapy (Figure 3). Patient had sustained palliation i.e, continuous relief of dysphagia for 4 months after radiotherapy.

\section{Discussion}

Primary malignant melanoma affecting the esophagus is a rare and fatal disease with a poor prognosis. Sabanathan et al. documented that approximately $50 \%$ of patients have metastatic disease at presentation and long-term survival is extremely rare [6]. The clinical presentation of primary malignant melanoma of the esophagus is similar to the common forms of primary esophageal malignancies. The tumor most commonly occurs in the $6^{\text {th }}$ and $7^{\text {th }}$
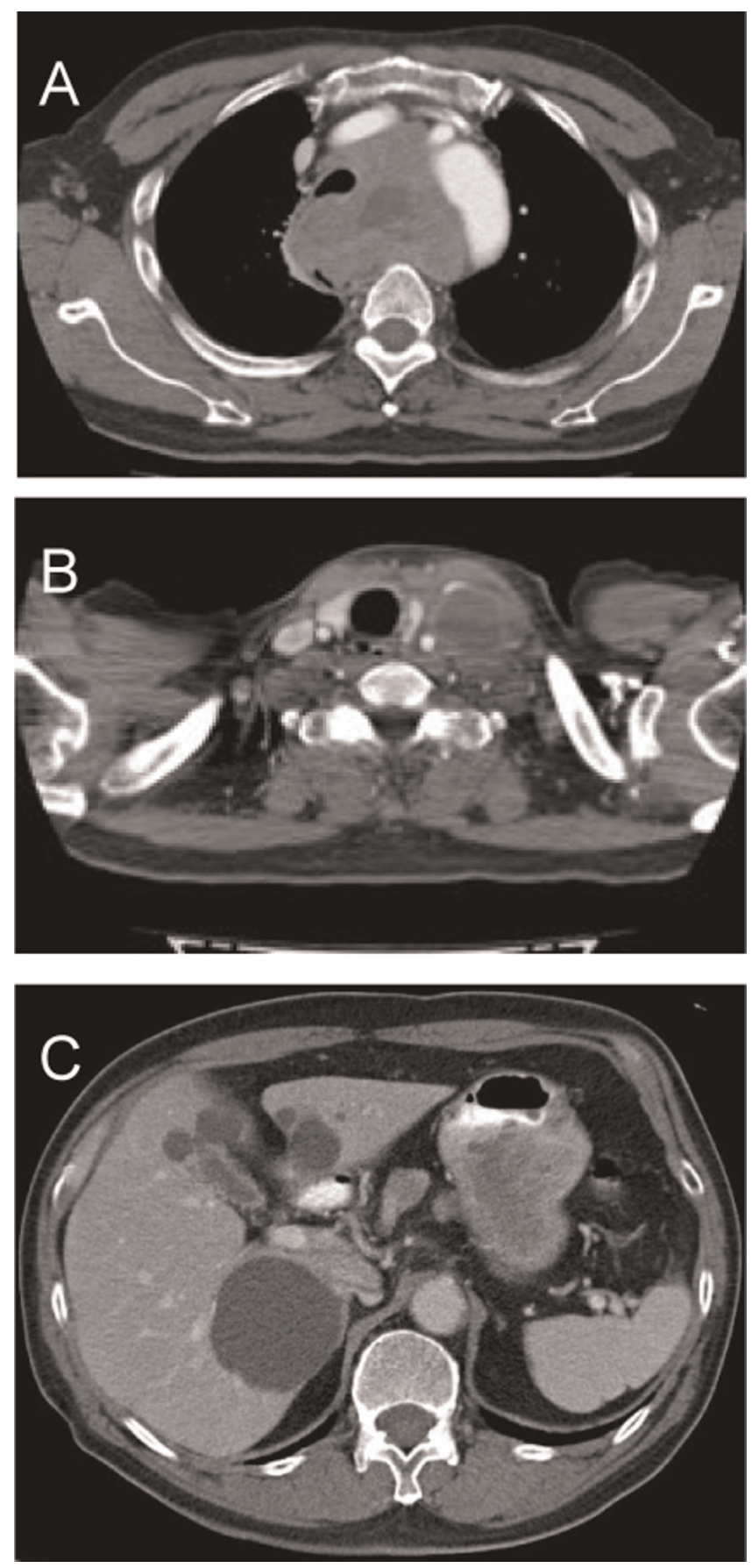

Figure I. Contrast enhanced CT showed $7.7 \mathrm{cms}$ mediastinal lymph nodes compressing the esophagus and trachea at the level of the aortic arch (A), $3.3 \times 3.0 \mathrm{cms}$ left supraclavicular (B) and $1.9 \times 1.5 \mathrm{cms}$ abdominal lymph nodes (C).

decade, and the male to female ratio is $2: 1$. Subtotal esophagectomy is recommended as the treatment of first choice for primary malignant melanoma of the esophagus. Sabanathan et al. reported a median survival of between 7 and 12 months in patients who underwent radical 


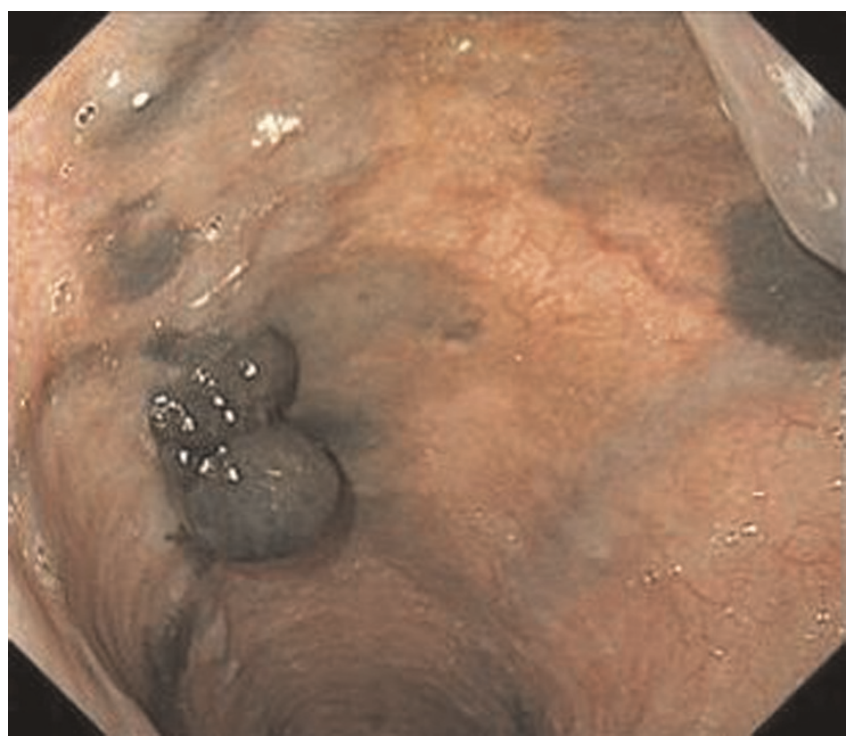

Figure 2. Endoscopic view of a dark gray polypoidal tumor of the esophagus at presentation.

resection and a 5 year survival of $4.2 \%$ [7]. Chalkiadakis et al. reported, in a series of 110 patients, a mean survival of 13 months [8]. However, at the time of diagnosis, some cases may be diagnosed as having inoperable carcinoma. Chemotherapy is one of the treatment options for malignant melanoma. However, it is difficult to use chemotherapy to elderly or poor performance status patients. Paul et al. reported that the response rate for dacarbazine alone was $16.9 \%$ and was $21.5 \%$ for dacarbazine plus immunotherapy [9]. Although radiotherapy may have a palliative role if surgery is not possible,

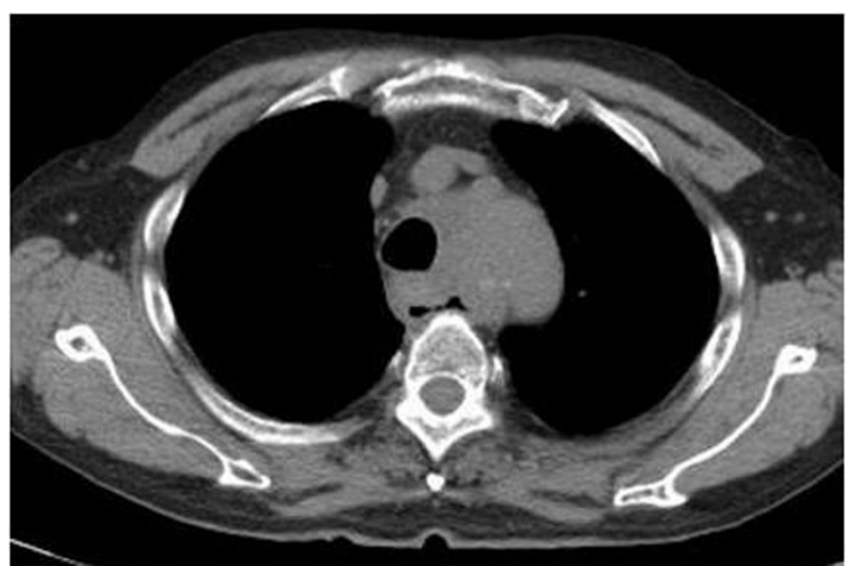

Figure 3. Mediastinal lymph node decreased in size on plain CT I week following completion of radiotherapy at the level of the aortic arch. malignant melanoma has been considered radioresistant [10]. At the time of diagnosis of the present case, multiple lymph node metastases were observed and the performance status was 3. Therefore, radical surgery and chemotherapy were not considered. There have been several case reports of effective palliation with photon radiotherapy $[11,12]$. Forgarty et al. reported that a patient with malignant melanoma of the esophagus received 36 Gy with a photon beam in six fractions given twice weekly, and CT after 4 months following completion of radiotherapy showed no residual mass [11]. In the present case, palliative radiotherapy using a once-daily fractionation of 3.0 Gy was offered, and the tumor markedly decreased in size and partial response was achieved.

\section{Conclusion}

Malignant melanoma of the esophagus is rare. Patients with advanced inoperable melanomas of the esophagus benefit from radiation therapy. Radiation therapy is effective for palliation.

\section{Consent}

Written informed consent was obtained from the daughter of the patient for publication of this case report and accompanying images. A copy of the written consent is available for review by the Editor-in-Chief of this journal.

\section{Competing interests}

The authors declare that they have no competing interests.

\section{Authors' contributions}

All authors contributed to acquisition of the case details and the analysis and interpretation of those details. All authors read and approved the final manuscript.

\section{References}

I. Mikami T, Fukuda S, Shimoyama T, Yamagata R, Nishiya D, Sasaki Y, Uno Y, Saito H, Takaya S, Kamata Y, Munakata A: A case of earlystage primary malignant melanoma of the esophagus. Gastrointest Endosc 200I, 53:365-367.

2. Kido $T$, Morishima $H$, Nakahara $M$, Nakao $K$, Tanimura $H$, Nishimura R, Tsujimoto $M$ : Early stage primary malignant melanoma of the esophagus. Gastrointest Endosc 2000, 51:90-91.

3. Caldwell CB, Bains MS, Burt M: Unusual malignant neoplasms of the esophagus. Oat cell carcinoma, melanoma, and sarcoma. J Thorac Cardiovasc Surg 1991, I01:100-107.

4. Naomoto Y, Perdomo JA, Kamikawa Y, Haisa M, Yamatsuji T, Kenzo A, Taguchi K, Hara K, Tanaka N: Primary malignant melanoma of the esophagus: report of a case successfully treated with pre- and post-operative adjuvant hormonechemotherapy. Jpn J Clin Oncol 1998, 28:758-76I.

5. International Union Against Cancer. TNM Classification of Malignant Tumours. 6th edition. New York: John Wiley \& Sons, Inc; 2002.

6. Sabanathan S, Eng J, Pradhan GN: Primary malignant melanoma of the esophagus. Am J Gastroenterol 1989, 84:|475-|48|.

7. Sabanathan S, Eng J: Primary malignant melanoma of the oesophagus. Scand J Thor Cardiobovasc Surg 1990, 24:83-85.

8. Chalkiadakis G, Wihlm JM, Morand G, Weill-Bousson M, Witz JP: Primary malignant melanoma of the esophagus. Ann Thorac Surg 1985, 39:472-475.

9. Chapman PB, Einhorn LH, Meyers ML, Saxman S, Destro AN, Panageas KS, Begg CB, Agarwala SS, Schuchter LM, Ernstoff MS, 
Houghton AN, Kirkwood JM: Phase III multicenter randomized trial of the Dartmouth regimen versus dacarbazine in patients with metastatic melanoma. Chapman J Clin Oncol 1999, 17:2745-275I.

10. Boulafendis D, Damiani M, Sie E, Bastounis E, Samaan HA: Primary malignant melanoma of the esophagus in a young adult. Am J Gastroenterol 1985, 80:417-420.

II. Fogarty GB, Tartaglia CJ, Peters LJ: Primary melanoma of the oesophagus well palliated by radiotherapy. Br J Radiol 2004, 77:1050-1052.

12. Mills SE, Cooper PH: Malignant melanoma of the digestive system. Pathol Annu 1983, 18:1-26.

\section{Do you have a case to share?}

Submit your case report today

- Rapid peer review

- Fast publication

- PubMed indexing

- Inclusion in Cases Database

Any patient, any case, can teach us something

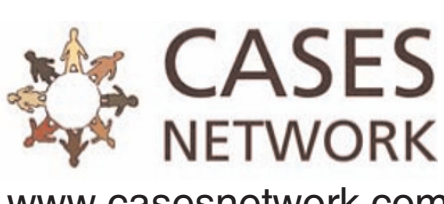

www.casesnetwork.com 